\title{
ELECTRODEPOSITION OF COPPER ON COPPER SINGLE CRYSTAL (100), (110) AND (111) PLANES IN PRESENCE OF THIOSEMICARBAZIDE
}

\author{
By B. S. Sheshadri and T. H. V. SetTy \\ (Department of Chemistry, Central College, Bangalore University, Bangalore-1) \\ Received April 20, 1972 \\ (Communicated by Prof. M. Santappa, F.A.sc.)
}

\begin{abstract}
Thiosemicarbazide (TSC), present in small quantities in acid copper sulphate bath, modifies the growth habits of copper on copper single crystal planes and reduces cathodic polarization. On (100) plane a transition from layer type of growth to ridge type and from ridges to pyramidal type and finally to polycrystalline type was noticed. On (110) plane ridges change to platelet type then finally to polycrystalline type. Cn (111) plane at low current densities triangular pyramids formed in pure solution transforms to hexagonal pyramids and to polycrystalline type. At high current densities hexagonal pyramids change to layer type, which transforms to nonsymmetrical pyramids and polycrystalline deposit at critical concentration of the addition agent. The transitions noticed derend on the concentrations of TSC and current density. These changes in morphology are attributed to the adsorption of TSC on the substrate.
\end{abstract}

IT is known ${ }^{1,2}$ that the epitaxial growth of copper depends largely on the orientation of the substrate and on the bath conditions. It is further shown ${ }^{3} \varsigma^{5}$ that in purified solutions characteristic growth occurs when copper is deposited on oriented copper surfaces. It is noticed ${ }^{3-7}$ also that habit modification takes place when deposition conditions are altered.

Addition agents used in plating baths to increase brightness, smoothness, etc., usually increase the cathodic polarization. ${ }^{8}$ There are, however, certain compounds which reduce the cathodic polarization. ${ }^{9}$ Thiosemicarbazide not only modifics the growth habits of copper on copper single crystal planes but also reduces the cathodic polarization when it is present in small quantities in acidified copper sulphate bath. 


\section{EXPERIMENTAL}

Preparation of highly purified solutions, electrolytic cell and general procedure are as in the earlier work. ${ }^{10}$ Known amount of TSC is added to highly purified $0.25 \mathrm{M} \mathrm{CuSO}_{4}+0.1 \mathrm{M} \mathrm{H}_{2} \mathrm{SO}_{4}$ and used.

\section{RESULTS}

Deposition on a (100) Face

At 2, 5 and $10 \mathrm{~mA} / \mathrm{cm}^{2}$ - Layer type of deposit was obtained (Fig. 1) when copper was deposited on a (100) face of copper single crystal from highly purified acid copper sulphate bath at 2,5 and $10 \mathrm{~mA} / \mathrm{cm} .{ }^{2}$, however the distance between the layers is large at 2 and $5 \mathrm{~mA} / \mathrm{cm}^{2}$ but small at $10 \mathrm{~mA} / \mathrm{cm}^{2}$. Layers with decreased distance between them were noticed when TSC was present in the bath in small yuantities. When TSC content was increased edge striations in these layers were noticed (Fig. 2). As the concentration of TSC was further increased more and more edge striations took place and a transition from layer to ridge type was noticed (Fig. 3). The layers completely broke up at striated points and gave ridge type of deposit (Fig. 4) when TSC was further increased. These ridges were aligned along [110] direction. Further increase in TSC content produced pyramidal type of growth (Fig. 5). Twinning of these pyramids (Fig. 6) and polycrystalline type of deposit (Fig. 7) resulted at higher concentration of TSC in the bath at all current densities.

Thus it was observed that a transition takes place from layer type of deposit to ridge type of deposit, from ridge type of deposit to pyramidal type of deposit, from pyramidal type to polycrystalline type of deposit in presence of TSC at three current densities mentioned above.

At $2 \mathrm{~mA} / \mathrm{cm}^{2}$, a transition from layers to ridges was observed at $4 \times 10^{-8}$ $\mathrm{M}$ TSC, which then transformed to pyramids at $5 \times 10^{-8} \mathrm{M}$. Finally, polycrystalline deposit was noticed at $1.5 \times 10^{-6} \mathrm{M}$ TSC.

In presence of $2.5 \times 10^{-7} \mathrm{M}$ TSC layers transformed to ridges when copper was deposited at $5 \mathrm{~mA} / \mathrm{cm}^{2}$. These ridges change to pyramidal type at $7.5 \times 10^{-7} \mathrm{M}$ in turn which transforms completely to polycrystalline tỳpe at $4 \times 10^{-6} \mathrm{M} \mathrm{TSC}$.

A transition at $10 \mathrm{~mA} / \mathrm{cm}^{2}$ from layers to ridges was noticed at $6.5 \times 10^{-7}$ $\mathrm{M}$ TSC. Ridges change to pyramidal type at $8 \times 10^{-7} \mathrm{M}$ TSC and polycrystalline type was obtained at $5 \times 10^{-6} \mathrm{M}$. 
At 15 and $20 \mathrm{~mA} / \mathrm{cm}^{2}$.-Layers, truncated pyramids (Fig. 8) were observed when copper was deposited from highly purified acid copper sulphate bath at $15 \mathrm{~mA} / \mathrm{cm}^{2}$. When the TSC content in the bath was increased from $10^{-8} \mathrm{M}$ to $10^{-6} \mathrm{M}$ the number of truncated pyramids decreased and blocks were observed. At $10^{-6} \mathrm{M}$ the number of truncated pyramids decreased and more of blocks were observed. Layers in the background gradually changed to ridge type of deposit (Fig. 9). At $1.5 \times 10^{-6} \mathrm{M}$ only ridge type of deposit was noticed ( $c f$. Fig. 4). Further increase in TSC content to $2.5 \times 10^{-6} \mathrm{M}$ pyramids with steps on their sides with ridge background appeared. At $5 \times 10^{-6} \mathrm{M}$ the surface was completely covered with stepped pyramids. Twinning of these pyramids took place when TSC content in the bath was increased to $7.5 \times 10^{-6} \mathrm{M}$. Small flat and twinned pyramids completely covered the surface at $10^{-5} \mathrm{M}$. At $1.5 \times 10^{-5} \mathrm{M}$, polycrystalline type of deposit resulted.

At $20 \mathrm{~mA} / \mathrm{cm}^{2}$ no regular transitions were observed when TSC was present in the bath, however there was gradual increase of block type of deposit. Twinned block type of deposit with occasional truncated pyramids were observed at $10^{-5} \mathrm{M}$ of TSC. At $2.5 \times 10^{-5} \mathrm{M}$ polycrystalline type of deposit resulted.

\section{Depositicn on a (110) Face}

At $5 \mathrm{~mA} / \mathrm{cm}^{2}$. - Ridge type of deposit (cf. Fig. 4) was observed when copper was deposited on a copper single crystal (110) face from highly purified acid copper sulphate bath as noticed earlier. They were aligned along [100] direction. When TSC content in the bath was varied from $10^{-8} \mathrm{M}$ to $10^{-7} \mathrm{M}$ these ridges become shorter. Further increase of TSC to $5 \times 10^{-7} \mathrm{M}$ there was a transition from ridges to platelets. At $10^{-6} \mathrm{M}$ concentration of TSC complete platelet type of deposit (Fig. 10) was observed. These platelets broke up with further increase of TSC and resulted in a polycrystalline type of deposit at $2.5 \times 10^{-6} \mathrm{M}$. It is shown ${ }^{10}$ that the type of growth did not change at different densities when copper was deposited on copper (110) from acid copper sulphate bath containing TSC except that the direction of ridges changes from [100] direction to [110] at 10 and $15 \mathrm{~mA} / \mathrm{cm}^{2}$; Hence further work was not carried out.

Deposition on a (111) Face

At $5 \mathrm{~mA} / \mathrm{cm}^{2}$.-Triangular pyramids with steps on their sides appcarcd (Fig. 11) when copper was deposited from highly purified acid copper sulphate bath on a copper single crystal (111) face. When TSC in the bath was 
increased from $10^{-10} \mathrm{M}$ to $10^{-9} \mathrm{M}$, the number of pyramids per unit area increased otherwise there was not much change in the deposit morphology. At $10^{-8} \mathrm{M}$ a tendency for twinning of these pyramids was observed but at $10^{-7} \mathrm{M}$ more of twinning of these pyramids was observed as seen in Fig. 12. At $10^{-6} \mathrm{M}$ of TSC there were occasional truncated triangular pyramids. On further increase in TSC content more of truncation of these twinned triangular pyramids was observed. At $10^{-5} \mathrm{M}$ and above these triangular pyramids gradually transformed to hexagonal type of pyramids. At $7 \cdot 5 \times 10^{-5} \mathrm{M}$ hexagonal pyramids with polycrystalline background appeared. The deposit consisted of more polycrystalline deposit with some truncated hexagonal pyramids when TSC was increased further. At $3 \times 10^{-4} \mathrm{M}$ the deposit was polycrystalline type.

At 10 and $15 \mathrm{~mA} / \mathrm{cm}^{2}$. - When deposited from highly purified acid copper sulphate bath truncated hexagonal pyramids with occasional triangular pyramids were observed at these current densities (Fig. 13). As the concentration of TSC in the bath increased the triangular pyramids got twinned and the number of hexagonal pyramids decreased. The triangular pyramids got truncated and truncated hexagonal pyıamids grew side ways and produced macrosteps (Fig. 14) when the concentration of TSC was further increased. When the content of TSC was increased distorted pyramids appeared and these were twinned (Fig. 15). Finally polycrystallıne type of deposit was observed at critical concentration of TSC.

At $10 \mathrm{~mA} / \mathrm{cm}^{2}$ truncated hexagonal and triangular pyramids transformed to macrosteps at $10^{-5} \mathrm{M}$ TSC, which then changed to distorted pyramidal type at $4 \times 10^{-5} \mathrm{M}$ and finally to polycrystalline deposit at $4 \times 10^{-4} \mathrm{M}$.

Truncated hexagonal and triangular pyramids obtained in pure solution changed to macrosteps at $2.5 \times 10^{-5} \mathrm{M} \mathrm{TSC}$ at $15 \mathrm{~mA} / \mathrm{cm}^{2}$. These macrosteps changed to distorted pyramidal type at $5 \times 10^{-5} \mathrm{M}$ TSC. Finally only polycrystalline deposit resulted at $5 \times 10^{-4} \mathrm{M}$ TSC.

At $20 \mathrm{~mA} / \mathrm{cm}^{2}$.-Both truncated hexagonal and occasional triangular pyramids ( $c f$. Fig. 13) were observed when deposited from pure solution. There was no change in the type of deposit when TSC was present in the bath upto a concentration of $10^{-5} \mathrm{M}$, however, there was increase of number of triangular pyramids. Large number of triangular pyramids with occasional truncated hexagonal pyramids (Fig. 16) were observed as the concentration of TSC was further increased. Some of the triangular pyramids were truncated. Twinning of these triangular pyramids resulted in polycrystalline type of deposit at critical concentration of TSC $\left(7 \cdot 5 \times 10^{-4} \mathrm{M}\right)$. 
More of TSC is needed to bring about the transformation on (111) face compared to those on (100) and (110) face.

\section{OVERPOTENTIALS}

On a (100) face.-When copper was deposited on a (100) face of copper single crystal, from highly purified solutions the overpotential increased with time and attained a steady value at all current densities investigated as observed by earlier workers., ${ }^{40,11}$ The steady value of overpotential was attained more or less at the same thickness of the deposit $\left(2 \mathrm{C} / \mathrm{cm}^{2}\right)$ at all current densities. When TSC was present in the bath same trend of increasing and attaining a steady state was observed. However overpotential was always lower at corresponding current densities in presence of TSC compared to pure solution. When ridge type of deposit grows the overpotential was practically constant from the beginning. The same trend was observed even when pyramids and polycrystalline type of deposits developed. However there was not much change in the values of overpotential during deposition from pure solution and in presence of TSC during deposition at $20 \mathrm{~mA} / \mathrm{cm}^{2}$.

The Tafel slope was found to be $125 \pm 5 \mathrm{mv}$ when deposited from highly purified solutions. There was no significant change in the values of Tafel slope and exchange current density when TSC is present in solution. The values of Tafel slopes and exchange current densities are shown in Table I.

On a (110) face.-The overpotential slightly increased and reached steady state value quickly during deposition on (110) face when deposited from pure solution. ${ }^{4}$ There was no change in the trend of variation of overpo:ential with time when TSC was present in the bath. The value of overpotential also did not change.

On a (111) face.-The overpotential values at all curient densities on a (111) face decreases and attains a constant value after some time when deposited from highly purified solution. ${ }^{4,10}$ When morphology of the deposit was affected by the presence of TSC the overpotential value was always lower compared to pure solution. However the same trend in change of overpotential with time was observed in presence of TSC. The steady state was attained more or less at the same thickness of the deposit.

The values of Tafel slope was found to be $130 \pm 5 \mathrm{mv}$ when deposited from highly purified solution for both initial and final values of overpoten- 
tial. ${ }^{4,10}$ The value of tafel slope and exchange currert density $\left(i_{0}\right)$ did not change much in presence of TSC. The values of Tafel slopes and exchange current densities are given in Table $I$.

TABLE I

Tafel slopes (b) and exchange current density ( $\left.i_{0}\right)$ in presence of TSC

\begin{tabular}{|c|c|c|c|c|c|}
\hline \multirow{2}{*}{ Plane } & \multirow{2}{*}{ Concentration of FSC } & \multicolumn{2}{|c|}{ Tafel slope (b) (mv) } & \multicolumn{2}{|c|}{$\begin{array}{c}\text { Exchange current } \\
\text { density }\left(\mathrm{i}_{0}\right) \cdot \mathrm{mA} / \mathrm{cm}^{2}\end{array}$} \\
\hline & & Initial & Steady & Initial & Steady \\
\hline \multirow[t]{4}{*}{$(100)$} & Pure solution & $125 \cdot 3$ & $120 \cdot 0$ & $3 \cdot 0$ & $1 \cdot 8$ \\
\hline & $10^{-8} \mathrm{M}$ & $136 \cdot 5$ & $140 \cdot 0$ & $2 \cdot 4$ & $2 \cdot 0$ \\
\hline & $10^{-2} \mathrm{M}$ & $144 \cdot 0$ & $140 \cdot 0$ & $3 \cdot 0$ & $2 \cdot 3$ \\
\hline & $10^{-6} \mathrm{M}$ & $141 \cdot 0$ & $1.41 \cdot 7$ & $2 \cdot 7$ & $2 \cdot 3$ \\
\hline \multirow[t]{4}{*}{ (111) } & Pure Solution & $132 \cdot 5$ & $130 \cdot 5$ & $1 \cdot 3$ & $1: 5$ \\
\hline & $10^{-6} \mathrm{M}$ & $145 \cdot 0$ & $144 \cdot 0$ & $2 \cdot 0$ & $1 \cdot 3$ \\
\hline & $10^{-5} \mathrm{M}$ & $146 \cdot 0$ & $142 \cdot 0$ & $2 \cdot 0$ & $1: 5$ \\
\hline & $10^{-4} \cdot M$ & $144 \cdot 0$ & $144 \cdot 9$ & $2 \cdot 8$ & 1.8 \\
\hline
\end{tabular}

Discussion

It is known ${ }^{12}$ that the morphology of electrodeposits may change because of the change of electrochemical parameters such as Tafel slope, exchange current density, etc., or due to adsorption of the addition agent on the surface of the substrate or both.

The above results indicate that there is no significant change in the Tafel slopes and exchange current densities in presence of TSC on all the three planes. Hence the mechanism of charge transfer has not changed in presence of TSC, i.e., the first electron transfer is the rate determining step even in presence of TSC. Therefore the above changes in the growth habits of copper electrodeposits may be due to only adsorption of TSC or the products produced during electrolysis.

Llopis $^{13}$ have shown by radio tracer method the presence of sulphur in copper deposits when deposited from acidified copper sulphate containing thiourea. Hence it can be assumed that TSC molecule, which is nothing 
B. S. Sneshadri and

Proc. Ind. Acad. Sci., A, Vol. LXXVI, Pl. IX.

T. H. V. Setty

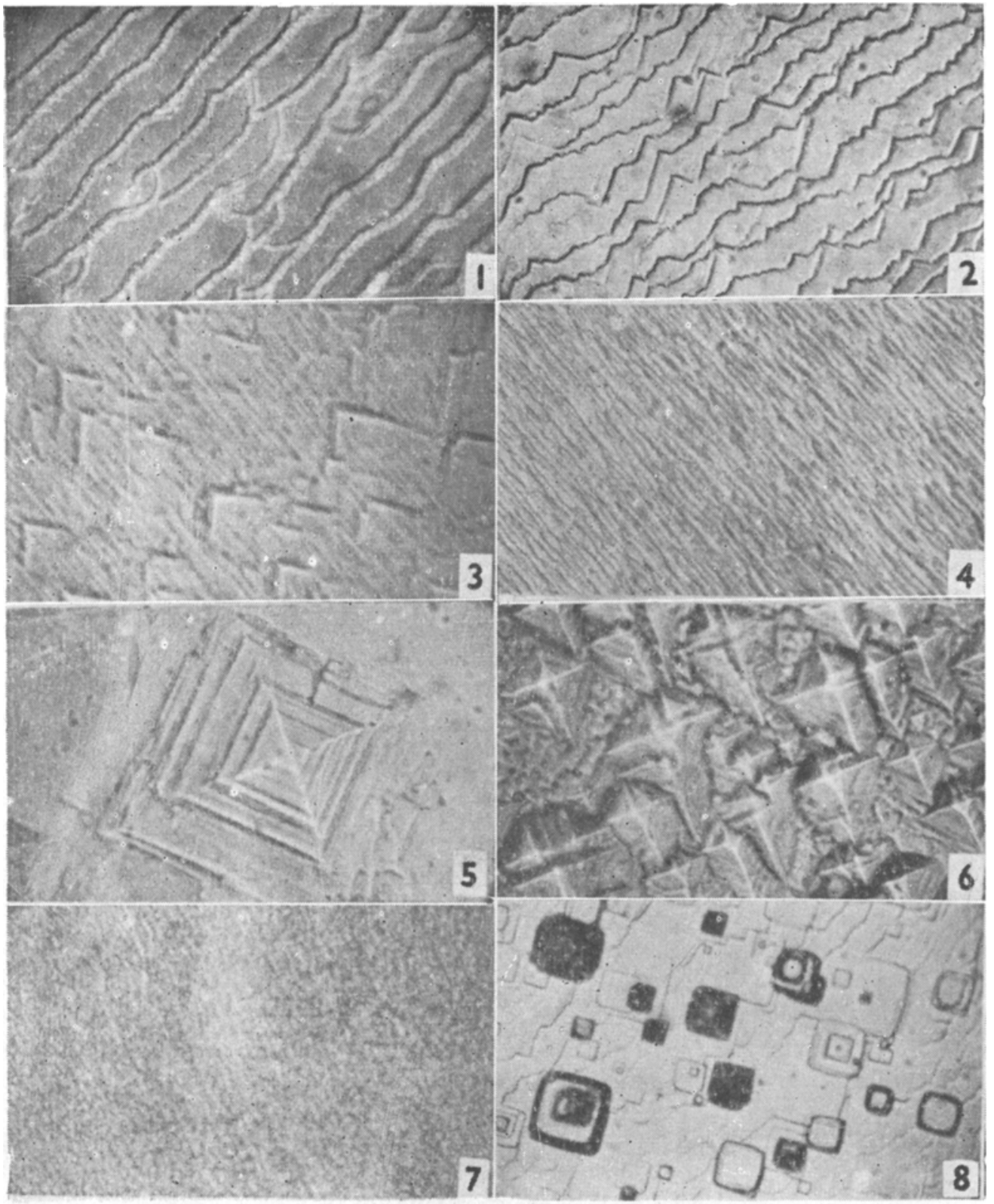

FIGS. 1-8 


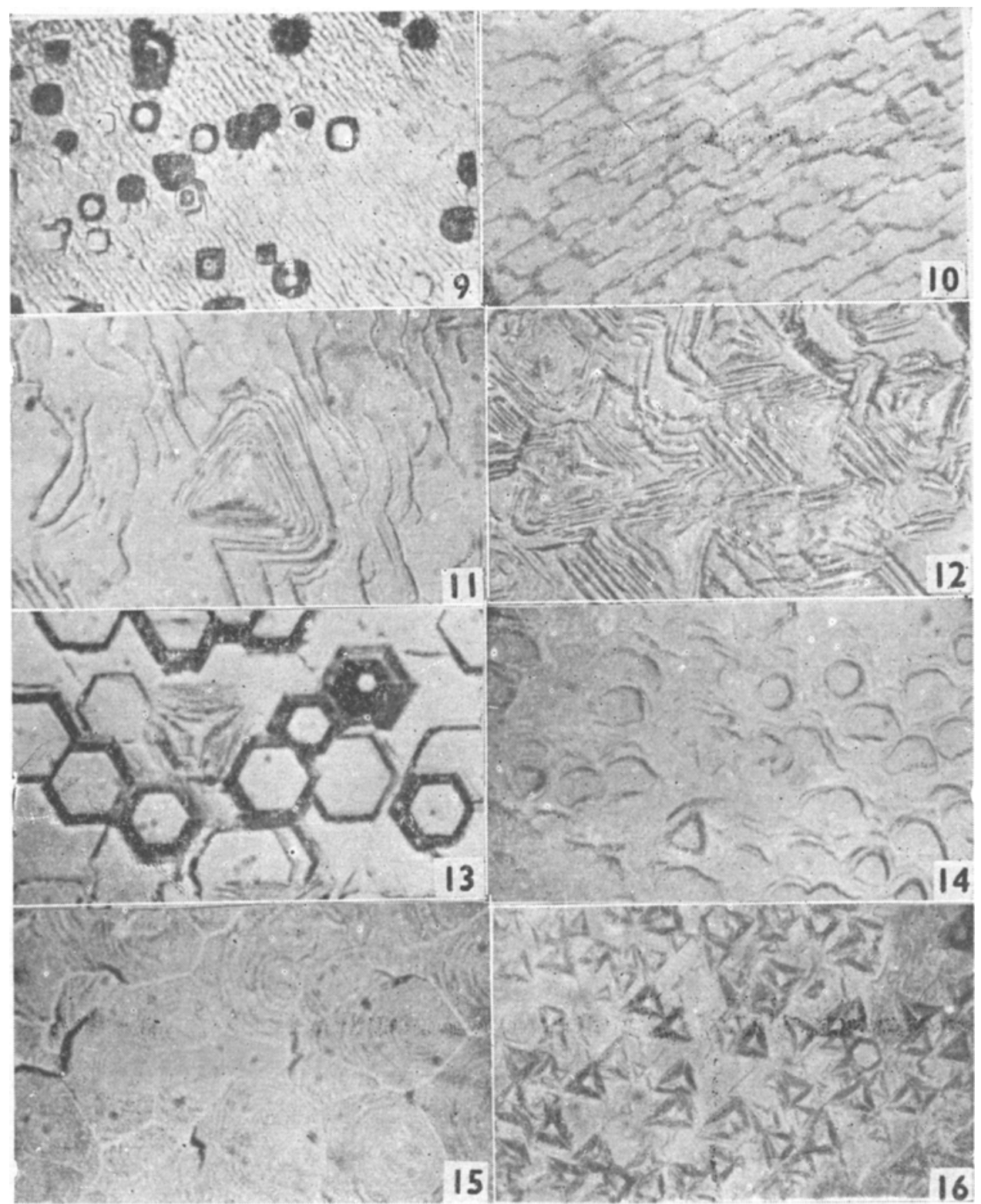

Figs. 9-16 
but amino-thiourea, may hydrolyse to give urea and hydrogen sulphide, or may be reduced at the cathode forming $\mathrm{NH}_{4} \mathrm{CN}$ and hydrogen sulphide. $\mathrm{Cu}^{++}$ions may react with hydrogen sulphide forming $\mathrm{CuS}$. Since solubility product of CuS is very low $\left(8.5 \times 10^{45} \mathrm{M}\right)$ the CuS wjll precipitate out on the cathode surface, relatively at low sulphide ion concentration. This precipitated CuS may get adsorbed at active sites on the cathode surface, and block the diffusion of adions or reduce the velocity of the movement of steps. Either way it interferes with normal crystal growth and thus bring about change in the deposit morphology.

The layers observed in pure acidified copper sulphate solution will transform to ridge type because of the hindrance of step movement on the surface by adsorbed film of CuS. The adions under this condition could only move along [110] direction on (100) face and crystallize at growth sites resulting in the ridge type of deposit. Here it is noticed that the cathodic polarization both on (100) face and (110) face are same during ridge type of growth and this supports the above observed fact. When TSC content in the bath is increased to a critical value, the CuS film may completely cover the active sites on the surface. Then the copper adions may nucleate on adsorbed film and growth of non-symmetrical pyramids on (100) face and platelet type of deposit on (110) face may form while the substrate stilf influences the growth. The frequency of nucleation may increase with the increase of TSC content and this will result in twinning of pyramids. More and more twinning takes place with the increase of TSC content. At a critical concentration, the twinned growth gives rise to polycrystalline type of deposit, as concluded by Setty and Wilman $^{14}$ for silver deposits.

On (111) plane at low current densities, regular triangular pyramids form. When TSC is present in the bath the number of such pyramids increased for the given area because of an adsorbed film of CuS on the surface which increases the growth nuclei. As the concentration of TSC is increased in the bath CuS may get adsorbed on the apex of these pyramids also. This prevents the vertical growth and the pyramids truncate. The truncated pyramids may now grow side ways. Further increase prevents this growth and there would be more nucleation producing blocks or nonsymmetrical pyramids which may get twinned. This twinned type may give rise to polycrystalline type of deposit.

\section{ACKNOWLEDGEMENT}

One of the authors (B.S.S.) is thankful to the Bangalore University for Research Assistantship. 


\section{REFERENCES}

1. Pick, H. J., Storey, G. G. Electrochim. Acta, 1960, 2, 165. and Vaughan, T. B.

2. Barnes, S. C., Storey, G. G. Ibid., 1960, 2, 195. and Pick, H. J.

3. Damjanovic, A., Paunovic, J. Electroanal. Chenı, 1965, 9, 93. M. and Bockris, J. O' M.

4. _— Setty, T. H. V. and J. Electrochem. Soc., 1966, 113, 429. Bockris, J. O'M.

5. Turner, D. R. and Ibid., 1962, 109, 778. Johnson, G. R.

6. Seiter, A., Fischer, H. and Electrochim. Acta, 1960, 2, 97. Albert, L.

7. Storey, G. G. and Barnes, Journal of Institute of Metals, 1962, 90, 336. S. C.

8. Shreir, L. L. and

Trans. Faraday Soc., 1954, 50, 393. Smith, J. W.

9. Barnes, S. C. .. J. Electrochem. Soc., 1964, 111, 296.

10. Sheshadri, B. S. and Setty, T. H. V.

11. Nageswara, S. and Setty, T. H. V.

12. Bockris, J. O'M. and Damjanovic, A.

Indian J. Chem., 1970, 8, 162.

Proc. Ind. Acad. Sci., 1968, B, 178.

Modern Aspects of Electrochemistry (Butterworth Scientific Publications, London), 1964, 3, 225.

13. Llopis, J., Gamboa, G. M. and Arzimendi, $\mathrm{L}$.

C.I.T.C.E., meeting Paris, Publications, Londen, 1951, p. 448. Butterworth.

14. Setty, T. H. V. and

Trans. Faraday Soc., 1955, 51, 391.

Wilman, $\mathrm{H}$.

\section{Explanation of Plates IX and $X$ \\ Plate IX}

FIG. 1. Copper deposited from acid copper sulphate bath on a (100) fece at $2 \mathrm{~mA} / \mathrm{cm},{ }^{2} 625 . \times$.

FIG. 2. Copper deposited from acid copper sulphate bath $+10^{-9} \mathrm{M}$ TSC on a (100) face at $2 \mathrm{~mA} / \mathrm{cm},{ }^{2} 625 \times$.

FIG. 3. Copper deposited from acid copper sulphate bath $+2 \times 10^{-8} \mathrm{M}$ TSC on a (100) face at $2 \mathrm{~mA} / \mathrm{cm}^{2}{ }^{2} 625 \times$.

FIG. 4. Copper deposited from acid copper sulphate bath $+2.5 \times 10^{-8} \mathrm{M}$ TSC on a (100) face at $2 \mathrm{~mA} / \mathrm{cm}^{2} 625 \times$. 
FIG 5. Copper deposited from acid copper sulphate bath $+6 \times 10^{-8} \mathrm{M}$ TSC on a $(100)$ face t $2 \mathrm{~mA} / \mathrm{cm}, 625 \times$.

FIG. 6. Copper deposited from acid copper sulphate bath $+2.5 \times 10^{-7}$ TSC on a (100) face at $2 \mathrm{~mA} / \mathrm{cm}^{2}{ }^{2} 625 \times$.

Fic. 7. Copper deposited from acid copper sulphate bath $+1.5 \times 10^{-6} \mathrm{M}$ TSC on a (100) face at $2 \mathrm{~mA} / \mathrm{cm},{ }^{2} 625 \times$.

Fig. 8. Copper deposited from acid copper sulphate bath on a $(100)$ face $a t 15 \mathrm{~mA} / \mathrm{rm},{ }^{2} 625 \times$.

\section{Plate X}

Fig. 9. Copper depesited from acid copper sulphate bath $+10^{-8} \mathrm{M}$ TSC on a (100) face at $15 \mathrm{~mA} / \mathrm{cm}^{2} 625 \times$.

FIG. 10. Copper deposited from ac d copper sulphate bath $+10^{-6} \mathrm{M}$ TSC on a (110) lace at $5 \mathrm{~mA} / \mathrm{cm}^{2}, 625 \times$.

FIG. 11. Copper deposited from acid copper sulph te bath on a (111) face at $5 \mathrm{~mA} / \mathrm{cm}^{2}, 625 . \times$

FIG. 12. Copper deposited from acid cepper sulphate bath $+10^{-7}$ MTSC on a (111) face at $5 \mathrm{~mA} / \mathrm{cm},{ }^{2} 625 \times$.

FIG. 13. Copper deposited from acid copper sulphate bath on a (111) face at $10 \mathrm{~mA} / \mathrm{cm}^{2}, 625 \times$.

FIG. 14. Copper deposited from acid copper sulphate bath $+10^{-5} \mathrm{M}$ TSC on a (111) face at 10 $\mathrm{mA} / \mathrm{cm}_{1},{ }^{2} 625 \times$.

FrG. 15. Copper deposited from acid copper sulphate bath $+5 \times 10^{-5} \mathrm{M}$ TSC on a (111) face at $10 \mathrm{~mA} / \mathrm{cm}^{2} 625 \times$.

Frg. 16. Copper deposited fiom acid copper sulphate beth $+5 \times 10^{-5} \mathrm{M}$ TSC on a (111) face at $20 \mathrm{~mA} / \mathrm{cm}^{2}{ }^{2} 625 \times$. 